\title{
LA EDUCACIÓN EN VALORES EN UN MUNDO GLOBALIZADO ${ }^{1}$
}

Hortensia Cuéllar Pérez

\section{RESUMEN}

El presente artículo aborda dos asuntos-problema: ¿Qué se entiende por globalización? ¿Es posible hablar de educación con valores en un mundo globalizado? Los estudios alrededor del primer tópico son variados y su abordaje se ha realizado desde distintos ángulos, como se recoge esquemáticamente aquí. Con relación al segundo, mucho se opina de valores en la educación pero, ¿es posible encontrar alguna institución pública que, de manera decidida, recomiende o trace grandes líneas de atención axiológica en el terreno educativo a nivel internacional? Es lo que intentaremos responder a continuación.

\section{ABSTRACT}

The present article is about two subjects-matters, dealed in a charted way. What is it understood by globalization? Is it possible to talk about education with values in a globalized word? The studies about the first topic are varied and have been discussed from different aspects, some of which are gathered here. Concerning the second topic, it is widely spoken 
about values in education but....It is possible to find diverse public institutions which strongly recommend or outline great lines of axiological attention on the educative grounds in an international level? This is what I try to answer in the following pages.

Palabras clave: sentidos de globalización; globalizacióngeneralización; derecho a la educación; valores; educación en valores.

\section{INTRODUCCIÓN}

El tema aparenta ser sencillo pero, en el fondo, se trata de un asunto complejo por la diversidad de elementos imbricados en su consideración. ¿Por qué? Porque el problema de la globalización, aún viniendo desde antiguo -así lo considera, por ejemplo Brudel-, adopta nuevos perfiles en el actual contexto internacional que la han convertido en una de las más fuertes categorías socioculturales contemporáneas; sin la globalización resulta casi imposible, hoy, encontrar explicación pertinente a diversos fenómenos.

Respecto al mundo de los valores, puede afirmarse algo semejante: aun cuando su tematización explícita corresponda específicamente a la modernidad filosófica, su vivencia es un problema de todos los días, como reconocemos por las experiencias personales de tipo axiológico que cada uno tenemos en los ámbitos familiar, escolar, laboral, sociopolítico, religioso, etcétera.

Y sobre la dimensión educativa, sabemos que ha sido preocupación de los grandes hombres y civilizaciones de la 
Historia, aun cuando su comprensión conceptual - ¿qué entendemos por educación?»-, haya estado sujeta a los avatares de la filosofía de los pueblos, las tradiciones, la moda e, incluso, a una excelente o deficiente Antropología que volvía más acertados o desacertados los diversos ensayos educativos a lo largo del tiempo. De este modo, por ejemplo, la educación en la Antigua Grecia tenía, al menos, dos versiones: la educación espartana y la helénica; en la Edad Media, la educación caballeresca y la monástica; en la contemporaneidad cultural, la educación para todos (con la que se designa los niveles básicos de educación) y la de élites (con todos los matices que esta expresión abarca) que corresponde a la educación artística y universitaria. $\mathrm{O}$, desde otra perspectiva, la consideración del conductismo o del humanismo en educación.

Ello indica que el mundo de los valores y su educación en un mundo globalizado, es un asunto que recibe diversos tratamientos y no sólo uno particular; como cuando señalamos: "la promoción de los valores en México", o "la promoción de valores en mi escuela o en el seno familiar", sino que -en virtud de su incidencia en todos los campos de la vida humanapodemos hablar, con pertinencia, de lo axiológico desde un ángulo más amplio o, dicho de otra manera, de una educación en valores en un mundo contemplado en perspectiva global.

¿Qué queremos señalar con ello? ¿Buscamos acaso las tendencias axiológicas (y por ende manifestativas de distintos tipos de filosofías) que mueven al mundo en nuestros días? ¿Cuáles son las mejores opciones para educar en valores actualmente? Interrogantes éstas que nos llevan a concretar cinco preguntas que se convierten en guía de nuestra exposición: 
I. ¿Qué entendemos por globalización?

II. ¿Es lo mismo universalización que globalización?

III. ¿Es posible educar en valores en un mundo globalizado?

IV. ¿Cuál es la situación -quasi a nivel geográficode este tipo de educación en el mundo?

V. ¿Qué valores deben cultivarse en un mundo globalizado?

\section{I. ¿QUÉ ENTENDEMOS POR GLOBALIZACIÓN?}

Las respuestas son diversas atendiendo al tipo de fuente al que acudamos y al nivel de profundización que busquemos, como lo muestra el siguiente acercamiento:

1) El sentido común nos indica que algo globalizado es aquello de cuyo valor pueden participar muchas personas. Por ejemplo: la Coca Cola o los automóviles Ford, que encontramos en todas partes del mundo; la llamada economía neoliberal, que aumenta el poderío de algunos países de Occidente, en desmedro de los más débiles; el idioma inglés; multitud de costumbres, como el uso de los jeans y de expresiones que entienden casi todos, como levantar una mano expresando el signo de victoria, etcétera.

2) Atendiendo al significado de la palabra, el Diccionario de la Real Academia Española entiende por "globalización" una derivación del adjetivo "global", que a su vez proviene de "globo" y que, al menos, tiene dos acepciones:
a) Algo que se refiere al globo terráqueo.
b) Algo tomado en conjunto. 
El sentido que implica la expresión globalización, como ahora la estamos utilizando, es la que se refiere al globo terráqueo.

3) Consultando a los especialistas, encontramos las siguientes metáforas para referirnos a la globalización:

a) Marshall McLuhan habla de aldea global, refiriéndose a las transformaciones de la vida y los medios de comunicación mundiales en nuestros días, con lo que indica que ya no existe rincón del planeta donde los medios de comunicación no incidan ${ }^{2}$. Se trata del apogeo de la era cibernética en donde -como afirma McLuhan- invadimos países enteros ya no con paquetes de productos perecederos, como en la Antigüedad, sino con paquetes de información, entretenimientos e ideas; la instantaneidad de la imagen y nuevos lenguajes, convierten en muy lenta a la prensa escrita y a otros instrumentos no electrónicos.

Derivado de esta situación, el orbe se "desterritorializa"; ya no existen fronteras sino las únicamente señaladas por el espacio cibernético -espacio-mundo-, que puede ser recorrido por quienes se instalen en él.

b) Para Immanuel Wallerstein la globalización adquiere, en cambio, la figura de "sistema-mundo" ${ }^{3}$, expresión con la que pretende denominar la sucesión ininterrumpida de los grandes sistemas económicos mundiales, bajo los cuales se ha construido la Historia y Geografía de los últimos tiempos (es 
decir, a partir del siglo XVI, de la Modernidad). Su óptica es eminentemente economicista y social, con lo que su versión podría ser una edición matizada del marxismo, al dejar de lado las categorías clásicas de la lucha de los opuestos señalando, sin embargo, con toda claridad, los tipos de mercantilismo y colonialismo que han imperado en la geoeconomía mundial de la Época Moderna. En nuestros días, el neoliberalismo -y más el neoliberalismo salvaje con todas sus consecuencias-, resulta un elemento más de análisis.

c) El caso de Ferdinand Braudel es semejante al de Wallerstein. Interpreta los movimientos globalizadores actuales -bajo el prisma de la economía y su correlato, el mercado-, llegando a forjar el concepto de "economía mundo". He aquí un texto suyo:

"Por economía mundo se entiende la economía del mundo globalmente considerado, "el mercado de todo el universo", como ya decía Simondi. Por economía mundo, término que forjé a partir del alemán Weltwirtschaft, entiendo la economía de una porción de nuestro planeta solamente, desde que forma un todo económico. Hace ya mucho tiempo que escribí que el Mediterráneo en el siglo XVI era, por sí solo (...), una economía mundo" ${ }^{4}$.

d) Octavio Ianni sostiene -en seguimiento de Joseph Grundwalt y Kenneth Flamm- que en la base de la internacionalización del capital está la formación, desarrollo y diversificación de lo que puede denominarse "fábrica global" 5 , en 
donde la producción e intercambio de productos comerciales -sobre todo entre las grandes potencias- se convierte en un hecho consuetudinario, sometido a las reglas que los mismos países-miembro establecen (pensemos en la Comunidad Europea que es el ejemplo mejor logrado de este experimento), o bien en las grandes compañías multinacionales para quienes, de hecho, no encontramos fronteras por falta de reglas, o en países como China que es el proveedor más grande en el macro-mercado global. El mundo se convierte, entonces, por obra y gracia de estos grandes movimientos comerciales y de producción, en un shopping center global.

e) En esta enorme combinación de Estados-Nación, de multiculturalismo y universalismo globalizador, emerge un elemento lingüístico común que es el idioma inglés convertido, a nivel mundial -como bien lo perciben Phillipson y Truchot ${ }^{6}$-, en el medio de comunicación ideal para superar esa Torre de Babel que es el planeta Tierra. Su buen uso y dominio permite las grandes transacciones comerciales, la comunicación en las relaciones internacionales, los tours de cualquier ciudadano del mundo que recorre el orbe, el intercambio científico, la transmisión de las grandes noticias mundiales, etcétera, permitiendo superar el regionalismo de la inmensa mayoría de los idiomas nacionales. Actualmente, el inglés -y el inglés bien hablado- es una condición de comunicación necesaria. De allí su importancia y predominio en el planeta entero.

Claude Truchot, L'Anglais dans le monde contemporain, Paris, Le Robert, 1990; Robert Phillipson, Linguistic Imperialism, Oxford, Oxford University Press, 1992. 


\section{II. ¿ES LO MISMO UNIVERSALIZACIÓN QUE GLOBALIZACIÓN?}

Así parece ser (al menos en sentido amplio, dejando de lado la dimensión lógico-semántica ${ }^{7}$ ), porque al referirnos a globalización entendemos que algo se está "universalizando" en nuestro mundo, que ya no hay fronteras, sino que lo globalizado se va expandiendo por todas partes con su influencia benefactora o destructora como ocurre, por ejemplo, con la economía neoliberal, los medios de comunicación masiva, los modelos democráticos de gobierno, ciertas modas y corrientes culturales, científicas o estéticas, el idioma inglés, etcétera. Por ello, el tipo de universalización de la globalización es una universalización sui-géneris en virtud de que su ámbito de ingerencia o aplicación tiene un radio de acción muy general, que comprende todos aquellos sitios del planeta en donde aquella moda, o esos parámetros económicopolíticos, o esos medios de comunicación, han llegado con su influencia.

Este hecho acarrea problemas epistémico-lingüísticos, imbricando lo teórico con lo práctico: las expresiones «universalización", "generalización", "globalización", siendo distintas, se encuentran íntimamente relacionadas cuando se habla de los problemas globales en el mundo actual, pues desaparecen los límites. Y es que, en teoría por supuesto, encontramos distinción entre ellos.

Si atendemos al sentido lógico de la expresión «lo universal", denota lo contrario a "lo individual", y su radio de acción, 
influencia, o injerencia es para todos, por lo que es omniabarcante e implica "validez para todos", como ocurre, por ejemplo, con el ser del hombre, su dignidad y derechos, cuestiones relacionadas con la verdad ontológica y ética de cada uno de los hombres y mujeres concretos, y no con el ejercicio del diálogo intercomunicativo e intersubjetivo de los dialogantes como fundamento de su validez.

Lo general, en cambio, teniendo un radio de acción mayor que el caso individual o particular, no cubre la totalidad de los casos, como cuando afirmamos: "generalmente llueve en septiembre" o "generalmente salgo de mi trabajo a las 6 p.m."; con lo que significo: "casi siempre llueve en septiembre" y "casi siempre salgo de mi trabajo a las 6 de la tarde", es decir, en la mayoría de los casos, con lo cual lo general no es regla universal sino en la mayoría de los casos. Es esto lo que ocurre de facto, cuando nos referimos a la globalización: abarca con su influencia muchísimas regiones del orbe, pero hay otras más que escapan a su influencia por diversas razones (tradiciones, costumbres, decisiones políticas equivocadas o ciertas, subdesarrollo, incultura, etcétera).

¿En qué sentido, entonces, se vinculan globalización y universalización? En un sentido amplio, no lógico, sino bajo el prisma de lo práctico a nivel social y cultural. Así, al hablar de ella, indicamos "mundialización" de aquello que se encuentra globalizado o está en tránsito de conseguirlo.

Tal característica resulta indicativa de la raigambre cultural-social del término "globalización", por contraposición a la matriz lógico-ontológica de los otros dos términos, con lo cual, tal expresión incluye un perfil claramente sociológico y 
práctico, utilizable para designar fenómenos humanos de "mundialización de algo en la aldea global. Ese "algo" puede adquirir rostros distintos aun cuando, el sentido originario de su acuñamiento en nuestros días, parece encontrarse en los medios de comunicación social e inmediatamente después en la economía.

\section{III. ¿ES POSIBLE EDUCAR EN VALORES EN UN MUNDO GLOBALIZADO?}

Con estos antecedentes, intentemos contestar: ¿Qué son los valores? ¿Es posible educar en valores en un mundo globalizado? ¿Cuál es la situación de este tipo de educación en el mundo actual? La respuesta, como siempre, no resulta sencilla por la combinatoria de elementos culturales, de concepción del hombre y educación, y de políticas públicas a nivel nacional e internacional que se encuentran involucradas.

Sobre la primera pregunta - ¿qué son los valores?»- la respuesta es muy compleja. En un acercamiento preliminar, sin embargo, señalaríamos que los valores, en general, son cierta especie de bienes de rango universal, que no excluye la consideración de los valores de emergencia local como acontece, por ejemplo, con el valor de las tradiciones o de las gestas históricas de cada pueblo, que de suyo poseen un horizonte de aplicación no universal. No así el hablar in génere de la tradición o de la gesta histórica, que qua talis se ha dado en todas las culturas del mundo, con lo que en ese sentido son de radio universal.

Ahora bien, la consideración de los valores desde la perspectiva de su propio estatuto ontológico nos hace afirmar que son tipos de cualidades y por lo mismo no son ens per se sino 
per accidens, característica que no les restringe importancia sino más bien nos hace conocer su esencia, y cuyo fundamento inmediato es el bien -trascendentalmente entendido y no sólo en sentido moral- y el ser que se constituye en su último fundamento. Y como la analogía del ente es muy amplia, en consecuencia los tipos de bienes y los valores se expresan de diversísimos modos.

Sobre las otras dos preguntas pendientes, partimos de un hecho que resulta incuestionable ${ }^{8}$, inviolable y sagrado: los seres humanos somos personas, únicas e irrepetibles, pero siempre abiertas al otro por nuestra condición social y trascendente. Con ello indicamos que somos seres pensantes y libres, con todos los derechos y deberes que una expresión así lleva consigo. En seguimiento de Scheler y la tradición del humanismo clásico de Occidente, admitimos que los seres humanos ocupamos un puesto peculiar en este universomundo, debido a nuestra espiritualidad creativa y libre, a nuestra racionalidad cognoscente que indaga tanto en lo esencial como en lo accidental, a nuestra personalidad capacitada para abrirse a los demás por el conocimiento y donarse generosamente por el amor, originando ámbitos de convivencia natural y ayuda recíproca al interior de la institución familiar y en la comunidad, al crear asociaciones e instituciones cuya finalidad de iure, debe ser la promoción de todo lo humano, como corresponde a la escuela, la Iglesia, el Estado, las asociaciones políticas, el sindicato, asociaciones filantrópicas, clubes culturales, relaciones de amistad, etcétera, para hacer este mundo nuestro más habitable, constructor de grandes civilizaciones y 
culturas, para así contrarrestar los excesos y violencias a los que la condición humana puede conducir `, por un afán desmedido de dominio y de ignorancia en lo humano, que encierra responsabilidades no sólo de tipo ético, sino también educativo, cultural y político.

Esto último, de facto, acarrea situaciones de injusticia, quebrantamiento de la paz e insolidaridad tanto al interior del clima más íntimo que se respira en la familia, como en la escuela, las relaciones sociales, laborales y de amistad, o el resquebrajamiento de las reglas justas bajo las que se rige la comunidad. Por eso es tan necesaria la educación bumana para la vida y durante toda la vida como recomienda la UNESCO, aunque de manera preponderante en los primeros años de vida de cualquier ser humano (educación básica), educación que, en cualquier caso, implica formación, culturización, mejora de las personas, enriquecimiento de su propio ser y proyección solidaria de lo bueno y noble que posee en la micro o macro comunidad a la que pertenece, así como el favorecimiento integral de los diversos aspectos de su personalidad y apertura esencial a los otros, sin destrucción -sino más bien cultivo- del hábitat natural y social que le circunda y ante el que le corresponde una responsabilidad compartida en su conservación y mejora.

En el impulso generoso a todos estos aspectos por parte de la familia, la escuela, el gobierno, la sociedad civil, etcétera, se encierra el famoso lema de "aprender a ser, aprender a conocer, aprender a hacer, aprender a vivir juntos con los 1970. 
demás, al descubrir al otro", que corresponden a los cuatro pilares de la educación para el siglo XXI que recomienda la UNESCO y donde también se acentúa, además, la necesidad del cuidado y promoción del ambiente.

Las recomendaciones de la UNESCO, sin embargo, se sustentan en una verdad más importante: la educabilidad del ser bumano "exigida" por su misma naturaleza, desde los primeros hasta los últimos años de su vida, sean éstos pocos o muchos, porque el proceso educativo es un proceso de mejora permanente que dura toda la vida. Y éste es un proceso de carácter intencional y libre donde se potencian y entrecruzan conocimientos, habilidades, destrezas, actitudes... valores y virtudes, que permiten hablar con conciencia, de que se busca la mejora de las personas tanto en el ámbito individual como en el comunitario, entendiendo estas expresiones en toda la riqueza que encierran.

Por tales razones, la ONU en su Declaración Universal de los Derechos del Hombre de 1948, estableció como uno de los derechos fundamentales de cualquier mujer u hombre, el derecho a la educación, que no indica que el estatuto de validez universal de los derechos que consagra radique en el acto político-social de tal Declaración y mucho menos en el juicio consensuado a que condujo la promulgación de tal Declaración. Una conclusión así sería absurda. Lo que se debe resaltar, es que tales derechos emanan de la consideración esencial de lo que es la persona humana, con todas sus exigencias y potencialidades, para ser tratada con dignidad y justicia, en un ambiente de libertad. De allí la valía universal de esas declaraciones, una de las cuales corresponde con todo derecho a la educación. 
El derecho a la educación es, por tanto, de estatuto universal. Plantear el tema de una educación en valores en un mundo globalizado se justifica plenamente, no en virtud de la globalización misma, sino de la gama de derechos fundamentales de la persona, uno de los cuales es el derecho a la educación que tiene por origen la dignidad de un ser de corte corpóreo-espiritual y siempre abierto a lo trascendente en virtud de su origen y destino. Esta afirmación es muy relevante.

\section{IV. ¿CUÁL ES LA SITUACIÓN -QUASI A NIVEL GEOGRÁFICO- DE ESTE TIPO DE EDUCACIÓN EN EL MUNDO?}

Con esto, pasamos a la siguiente interrogante. La respuesta -ya lo afirmamos- es casi geográfica y, por lo mismo, muy limitada y puede contestarse, al menos, en tres niveles:

a) Mostrar un mapa general de la investigación axiológica que se está realizando en el mundo.

b) Algunas universidades que cuentan con programas de posgrado sobre educación en valores.

c) Organismos y asociaciones internacionales que impulsan la investigación y praxis axiológica.

a) Comenzando por el "mapa axiológico", únicamente mencionaremos diferentes países donde este tipo de investigación resulta relevante o empieza a adquirir importancia. En América: Canadá, Estados Unidos, México, El Salvador, Colombia, Chile, Argentina; en Europa: España, Reino Unido, Suiza, Dinamarca; en Asia: China, Israel, Japón, Filipinas. 
Mi fuente de información es el Reporte de Documentación Internacional sobre Educación con Valores, de la Dirección Internacional de Relaciones Internacionales de la SEP (2002) ${ }^{10}$, que lo organiza atendiendo a los siguientes tres criterios:

1. Descripción de políticas y prácticas a nivel nacional y local.

2. Evaluación o discusión sobre prácticas a nivel nacional.

3. Propuestas teórico-metodológicas.

Los programas e iniciativas que abarca son de orden diverso: educación básica, media y superior, experiencias relevantes, artículos destacados, etcétera. Su presentación esquemática la recogemos al final de este escrito, presentándola como un anexo.

b) Sobre las universidades del mundo que cultivan este tipo de programas encontramos en Estados Unidos, las de Princeton, Boston y Ducke, interesadas en la investigación de los valores y la formación del carácter. En México, a la Universidad Panamericana (sede Ciudad de México), con su Maestría en Valores para la Acción Educativa (MAVAE), de próxima implementación probablemente en el nivel oficial mediante un acuerdo interinstitucional con el gobierno de México; en España, la Universidad de Barcelona con su Maestría en Ética; en Filipinas, la Universidad de Asia y el Pacífico que cuenta con una maestría muy exitosa en el sureste asiático,

${ }^{10}$ Cfr. Reporte de Documentación Internacional sobre Educación en Valores (Comp. por Nadina Naime y María Eugenia Ocampo Granados), Dirección General de Relaciones Internacionales, SEP. 2002. Presento al final del artículo un Anexo, recogiendo algunos de sus datos. 
sobre Ética y Axiología. Como se observa, el panorama del que tenemos conocimiento, en este aspecto, es muy limitado.

A nivel de asociaciones y organismos internacionales que incluyen como misión o política el cultivo y promoción de la investigación y praxis axiológica en el mundo, encontramos la International Society of Values Inquiry con sede en Búfalo, Nueva York; la UNESCO; y para América Latina la Organización de Estados Iberoamericanos (OEI), cuyas recomendaciones han generado diversas políticas y líneas de acción para los países del continente cara al siglo XXI. En este tenor, la Constitución de la UNESCO, en uno de sus artículos proclama:

"El descubrimiento de la multiplicidad (...) conduce a la búsqueda de valores comunes adecuados para establecer la solidaridad "intelectual y moral de la humanidad", "1.

Con ello significan que:

"La educación tiene pues una responsabilidad particular que ejercer en la edificación de un mundo más solidario (...). En cierta forma debe contribuir al nacimiento de un nuevo humanismo, con un componente ético esencial y amplio lugar para el conocimiento y para el respeto de las culturas y los valores espirituales de las diferentes civilizaciones, contrapeso necesario a una globalización percibida sólo en sus aspectos económicos y técnicos. El sentimiento de compartir valores y un destino comunes, constituye en definitiva el fundamento de cualquier proyecto de cooperación internacional, ${ }^{12}$.

${ }^{11}$ Tomado de Jacques Delors, La educación encierra un tesoro, México, Ediciones UNESCO, 1997, p.46.

12 Ídem, las cursivas son nuestras. 


\section{V. ¿QUÉ VALORES DEBEN CULTIVARSE EN UN MUNDO GLOBALIZADO?}

Nos resta una última interrogación: ¿Qué valores requieren tomarse en cuenta, para educar eficazmente, en la aldea global? Las recomendaciones de la UNESCO son reveladoras sobre el particular, recomendaciones que por su contenido se encuentran vinculadas, de alguna manera, al humanismo clásico de Occidente. Dividiremos la respuesta en dos segmentos:

\section{La Necesaria Inclusión de los Cuatro Pilares Básicos de la Educación}

a) "Aprender a ser" que constituye un enérgico llamado a que la educación debe contribuir "al desarrollo global de cada persona: cuerpo y mente, inteligencia, sensibilidad, sentido estético, responsabilidad individual, espiritualidad" ${ }^{13}$, que es otra manera de decir: "hay que favorecer la educación integral de las personas", o "la educación holística" en afirmación de Karan Singh ${ }^{14}$, ex Ministra de Educación de la India y miembro de la Comisión Internacional de la UNESCO para la educación del siglo XXI.

Con esto se significa que ninguna de las dimensiones de la personalidad del ser humano debe descuidarse, atendiendo a su dignidad y derechos (particularmente el derecho a la vida, la educación, vivienda, cuidado de la salud, etcétera).

\footnotetext{
Ídem, p.100.

${ }^{4}$ Karan Singh, "Educar para la sociedad global", en Jacques Delors, La educación encierra un tesoro, p.259. Aquí afirma: "La educación holística debe tener en cuenta las múltiples facetas -física, intelectual, estética, emocional y espiritual- de la personalidad y tender de ese modo a realizar el sueño eterno de forjar seres humanos perfectamente cabales que vivan en un mundo en el que impere la armonía".
} 
De allí que la formación para la vida no indica, únicamente, preparar para el mundo laboral sino atender a la dimensión intelectual, ética, estética, social, afectiva, espiritual, política, de cuidado y promoción de la salud, de educación en la libertad y la solidaridad... -que dan lugar a la denominación curricular de «educación física, educación afectiva, educación intelectual, educación moral, educación cívica", etcétera-, que de manera particular la escuela favorece, pero que no exime de derechos y responsabilidades a lo que otras instituciones educativas puedan aportar como es el caso de la familia (comunidad originaria de la persona), el ámbito social, el Estado, la Iglesia, los medios de comunicación, etcétera.

b) "Aprender a conocer" que está dirigida a la apertura de los diversos campos del saber y adquisición de conocimientos que pueden ser teórico-prácticos, a fin de que cada persona "aprenda a comprender el mundo que le rodea, al menos suficientemente para vivir en dignidad, desarrollar sus capacidades profesionales y comunicarse con los demás. Como fin, su justificación es el placer de comprender, de conocer de descubrir" ${ }^{15}$.

Esto incluye una cultura general y la especialización en algún campo que lleve al conocimiento de nuevos lenguajes culturales y al uso adecuado de las nuevas tecnologías de la información al servicio de una educación de calidad.

Asunto relevante en este rubro, es no olvidar que todo conocimiento -si lo es-conduce al tema de la verdad-que como valor y realidad no es posible evadir, si estamos hablando 
de "saber"- y a la que, en ocasiones, se le evade por los compromisos intelectuales y éticos que su vislumbramiento lleva consigo.

La formación del sentido crítico, por ejemplo, implica formación de la inteligencia, facultad cognoscitiva que nos permite inteligir, conocer algo o mucho del mundo que nos rodea, y que permanentemente está abierta al saber.

Por tanto, una educación de calidad enseña no solamente a pensar, sino a conocer y tener admiración por la adquisición de la verdad, desarrollando el sentido crítico y el amor por la ciencia.

c) "Aprender a hacer". Para la UNESCO, esta recomendación se vincula estrechamente a la formación profesional y adquisición de competencias desde la más tierna infancia ${ }^{16}$. Por eso se pregunta: “Cómo enseñar al alumno a poner en práctica sus conocimientos y, al mismo tiempo, cómo adaptar la enseñanza al futuro mercado de trabajo, cuya evolución no es totalmente previsible?" ${ }^{17}$.

El "aprender a hacer" se enfoca a la preparación profesional para la vida (facere), asunto que no está mal y siempre es importante en el ámbito laboral, pero deja de lado, sin embargo, aquello que los clásicos denominaban el agere, es decir, la dimensión ética de la persona que le conducirá no solamente a ser un buen trabajador, sino un buen hombre y que tiene que ver con otro valor importantísimo que es el del cultivo del bien. Entramos, así, a la dimensión moral de la persona concreta que requiere una esmerada educación desde la 
infancia, porque se relaciona con tópicos tan importantes como la educación de la libertad, responsabilidad, amor, generosidad, aceptación del otro, tolerancia, generosidad, comprensión y ayuda al desvalido, laboriosidad, honor, amistad, respeto en sus diversos niveles (a los padres, maestros, autoridad legítima, la patria...), etcétera.

La formación ética de la persona, por tanto, se convierte en uno de los valores que a nivel global es necesario cultivar con mayor ahínco, tanto en su vertiente privada como pública. Esto nos da pauta para considerar el último pilar básico de la educación.

d) "Aprender a vivir juntos, aprender a vivir con los demás". Es indudable que este aprendizaje constituye una de las principales empresas de la educación contemporánea vista en perspectiva global. Las guerras, la violencia recurrente en las diversas esferas de la vida social, la esclavitud, el dominio despótico, la crueldad y falta de conciencia ética manifiesta en los fenómenos de corrupción, narcotráfico, droga, terrorismo, etcétera, exigen que recordemos los principios básicos de la convivencia -enraizados en una formación cívica y ética en concordancia con lo que la naturaleza humana exige-, es decir, con aquello que hace bueno al ser humano tanto a nivel personal, como social. De allí la necesidad de la práctica del bien, el cultivo de la verdad y el ejercicio de la justicia, reconociendo con toda generosidad las propias cualidades y virtudes, así como las del vecino - las del otro- con quien puedo vivir en armonía, conociéndole mejor en su historia, tradiciones, espiritualidad. La aceptación del otro es aplicable a todos los ámbitos de la vida: familiar, escolar, cívica, laboral, empresarial, deportiva, política, etcétera. 


\section{2. ¿Qué Otros Valores es Necesario Recomendar} para Responder al Requerimiento de una Educación en Valores en un Mundo Globalizado?

Mencionaré solamente algunos imbricados, como resulta connatural a su esencia, en multitud de realidades de la vida corriente:

a. Todos aquéllos relacionados con la célula básica de la sociedad que es la familia, desarrollando políticas que conserven su integridad e importancia tanto en el ámbito local, nacional y mundial.

b. Con relación a la escuela, remarcar el lugar esencial del maestro en la formación de sus alumnos porque, de una manera relevante, le corresponde "trasmitir al alumno lo que la humanidad ha aprendido de sí misma, todo lo que ha creado e inventado de esencial", promoviendo su propia autoeducación vía la capacitación permanente y su propia conciencia de que "el maestro siempre es un ejemplo".

La escuela, además, se convierte en fuente permanente de cultura y ámbito privilegiado donde se favorece el saber y el arte, el trabajo solidario, el compañerismo y la amistad, realidades todas ellas que proyectan multitud de valores.

c. No dejar nunca de lado la valía de las verdades esenciales de cualquier educación humanista. Ésta se resume en la práctica y conocimiento de los derechos humanos, la adquisición de hábitos buenos y de virtudes que pueden tener como objetivo educar en y para la libertad, igualdad, práctica de la justicia, bien, belleza, verdad, 
solidaridad, tolerancia, laboriosidad, responsabilidad, conmiseración del otro, ayuda a los débiles, etcétera, que se resumen en la vivencia del amor.

d. La educación para la paz y el espíritu de concordia, encierra así también un amplio horizonte axiológico vinculado con la justicia y el actuar prudencial en las diversas dimensiones de la vida. El aprecio de lo multicultural y las tradiciones regionales y locales adquiere aquí un papel preponderante.

e. Favorecer los valores ecológico-ambientales con lo que implican de respeto y promoción del universo-tierra.

f. Fomentar el aprecio y la conciencia de que la revolución en los medios de comunicación y nuevas tecnologías son fruto del genio y creatividad humanos, por lo que resul$\tan$ medios -y no fines- al servicio del hombre y no a la inversa. 


\section{ANEXO \\ REPORTE BREVE DE DOCUMENTACIÓN INTERNACIONAL "Educación con valores»}

\section{Descripción de Políticas y Prácticas a Nivel Nacional y Local}

\begin{tabular}{|c|c|c|c|}
\hline TíTULO & REFERENCIA & PAÍS & COMENTARIOS \\
\hline $\begin{array}{l}\text { Iniciativas relaciona- } \\
\text { das con la educación } \\
\text { en valores: } \\
\text { "Grade } 7 \text { Values Day», } \\
\text { "Fairplay», } \\
\text { "Evelyn Richardson } \\
\text { Memorial Elementary } \\
\text { School. Disciplinary } \\
\text { Handbook». }\end{array}$ & $\begin{array}{l}\text { Nova Scotia, Canada. } \\
\text { Department of } \\
\text { Education. }\end{array}$ & $\begin{array}{l}\text { Canadá (Nova } \\
\text { Scotia). }\end{array}$ & $\begin{array}{l}\text { Se presenta una breve } \\
\text { descripción de los dos } \\
\text { primeros programas y } \\
\text { el texto completo del } \\
\text { manual de disciplina } \\
\text { del tercer programa. } \\
\text { El tercer programa } \\
\text { manifiesta el interés } \\
\text { de incluir valores rela- } \\
\text { cionados con el respeto } \\
\text { para mejorar la discipli- } \\
\text { na escolar. }\end{array}$ \\
\hline $\begin{array}{l}\text { Iniciativas relaciona- } \\
\text { das con la educación } \\
\text { para un clima positivo } \\
\text { en la escuela. }\end{array}$ & $\begin{array}{l}\text { New Found and } \\
\text { Labrador, } \\
\text { Canada. Department } \\
\text { of Education. }\end{array}$ & $\begin{array}{l}\text { Canadá (New } \\
\text { Found and } \\
\text { Labrador). }\end{array}$ & $\begin{array}{l}\text { Esta descripción de } \\
\text { iniciativas refleja la } \\
\text { especial preocupación } \\
\text { por disminuir el clima } \\
\text { de violencia y de } \\
\text { indisciplina que priva } \\
\text { en las escuelas. }\end{array}$ \\
\hline $\begin{array}{l}\text { "The Partnerships in } \\
\text { Character Education } \\
\text { Pilot Project } \\
\text { Program». }\end{array}$ & $\begin{array}{l}\text { U.S. Department of } \\
\text { Education. }\end{array}$ & $\begin{array}{l}\text { Estados } \\
\text { Unidos. }\end{array}$ & $\begin{array}{l}\text { Se enuncia el marco } \\
\text { reglamentario para el } \\
\text { diseño y aplicación de } \\
\text { proyectos de educa- } \\
\text { ción del carácter. }\end{array}$ \\
\hline
\end{tabular}




\begin{tabular}{|c|c|c|c|}
\hline TíTULO & REFERENCIA & PAís & COMENTARIOS \\
\hline $\begin{array}{l}\text { "Character Education } \\
\text { Partnership». }\end{array}$ & $\begin{array}{l}\text { Character Education } \\
\text { Partnership. }\end{array}$ & $\begin{array}{l}\text { Estados } \\
\text { Unidos. }\end{array}$ & $\begin{array}{l}\text { Esta asociación traba- } \\
\text { ja a nivel nacional y } \\
\text { desarrolla actividades } \\
\text { que van desde la } \\
\text { investigación, evalua- } \\
\text { ción y difusión de la } \\
\text { educación del carácter, } \\
\text { particularmente en los } \\
\text { niveles de educación } \\
\text { básica. } \\
\text { Se adjunta una breve } \\
\text { descripción del progra- } \\
\text { ma, así como los once } \\
\text { principios de una edu- } \\
\text { cación efectiva del } \\
\text { carácter, criterios con } \\
\text { los cuales diseñan } \\
\text { todas sus actividades. }\end{array}$ \\
\hline $\begin{array}{l}\text { «Character Education } \\
\text { Network». }\end{array}$ & $\begin{array}{l}\text { Centre for the } \\
\text { Advancement of } \\
\text { Ethics and Character, } \\
\text { Boston University, } \\
\text { School of Education. }\end{array}$ & $\begin{array}{l}\text { Estados } \\
\text { Unidos. }\end{array}$ & $\begin{array}{l}\text { Se anotan los datos } \\
\text { generales para con- } \\
\text { tactar esta red y esta- } \\
\text { blecer intercambio de } \\
\text { información sobre el } \\
\text { tema. }\end{array}$ \\
\hline $\begin{array}{l}\text { "How America's } \\
\text { School Boards Are } \\
\text { Promoting Values and } \\
\text { Virtues". }\end{array}$ & $\begin{array}{l}\text { National School } \\
\text { Boards. }\end{array}$ & $\begin{array}{l}\text { Estados } \\
\text { Unidos. }\end{array}$ & $\begin{array}{l}\text { Se presenta la ficha } \\
\text { temática de esta } \\
\text { publicación que es la } \\
\text { séptima, de una serie } \\
\text { de publicaciones que } \\
\text { describen las mejores } \\
\text { prácticas en distritos } \\
\text { escolares en Estados } \\
\text { Unidos. Describe más } \\
\text { de doscientos progra- } \\
\text { mas que se han usado } \\
\text { para enseñar valores } \\
\text { básicos como el res- } \\
\text { peto y la responsabili- } \\
\text { dad. }\end{array}$ \\
\hline
\end{tabular}




\begin{tabular}{|c|c|c|c|}
\hline TítULO & REFERENCIA & PAís & COMENTARIOS \\
\hline «Kenan Ethics». & $\begin{array}{l}\text { The Kenan Institute } \\
\text { for Ethics, } \\
\text { Ducke University. }\end{array}$ & $\begin{array}{l}\text { Estados } \\
\text { Unidos. }\end{array}$ & $\begin{array}{l}\text { El programa de este } \\
\text { instituto se enfoca en } \\
\text { tres áreas: } \\
\text { - Ética a través del } \\
\text { currículum. } \\
\text { - Ética en la vida del } \\
\text { campus (Duke } \\
\text { University). } \\
\text { - Ética dentro y a tra- } \\
\text { vés de las comunida- } \\
\text { des. } \\
\text { Promueve diversos } \\
\text { proyectos algunos de } \\
\text { los cuales se encuen- } \\
\text { tran referidos en el } \\
\text { documento que se } \\
\text { presenta. }\end{array}$ \\
\hline $\begin{array}{l}\text { Programa Nacional de } \\
\text { Educación 2001-2006. }\end{array}$ & $\begin{array}{l}\text { Secretaría de } \\
\text { Educación Pública. }\end{array}$ & México. & $\begin{array}{l}\text { Documento que } \\
\text { expresa las políticas, } \\
\text { objetivos y metas que } \\
\text { el Gobierno Federal } \\
\text { promueve en México } \\
\text { a nivel nacional. Parte } \\
\text { de los objetivos y } \\
\text { estrategias del Plan } \\
\text { Nacional de } \\
\text { Desarrollo, conside- } \\
\text { rando la complejidad } \\
\text { de los cambios educa- } \\
\text { tivos que es necesario } \\
\text { emprender para que el } \\
\text { país asegure un desa- } \\
\text { rrollo sustentable. }\end{array}$ \\
\hline
\end{tabular}




\begin{tabular}{|c|c|c|c|}
\hline TíTULO & REFERENCIA & PAíS & COMENTARIOS \\
\hline $\begin{array}{l}\text { La definición política } \\
\text { de valores en la refor- } \\
\text { ma educativa. }\end{array}$ & $\begin{array}{l}\text { Picardo Joao, Oscar. } \\
\text { «Realidades } \\
\text { Educativas: Teoría y } \\
\text { Praxis Contemporáneas». } \\
\text { Ediciones Universidad } \\
\text { de El Salvador, } \\
\text { Informe-UES 2000. } \\
\text { En Organización de } \\
\text { Estados lberoamericanos } \\
\text { para la Educación la } \\
\text { Ciencia y la Cultura. }\end{array}$ & El Salvador. & $\begin{array}{l}\text { Es un capítulo del } \\
\text { libro que se consigna } \\
\text { en la referencia y da } \\
\text { cuenta de algunas } \\
\text { actividades innovado- } \\
\text { ras que se han impul- } \\
\text { sado en este tema. }\end{array}$ \\
\hline $\begin{array}{l}\text { Lineamientos curricu- } \\
\text { lares para el área de } \\
\text { Ética y Valores } \\
\text { Humanos. } \\
\text { Orientaciones para la } \\
\text { formulación de los } \\
\text { currículos en } \\
\text { Constitución Política y } \\
\text { Democracia. }\end{array}$ & $\begin{array}{l}\text { República de Colombia. } \\
\text { Ministerio } \\
\text { de Educación } \\
\text { Nacional. Dirección } \\
\text { General de } \\
\text { Investigación y } \\
\text { Desarrollo Pedagógico. } \\
\text { Grupo de Investigación } \\
\text { Pedagógica. (1998) } \\
\text { En Organización de } \\
\text { Estados } \\
\text { lberoamericanos para } \\
\text { la Educación la Ciencia } \\
\text { y la Cultura. }\end{array}$ & Colombia. & $\begin{array}{l}\text { Para la realización de } \\
\text { estos lineamientos, } \\
\text { contaron con la aseso- } \\
\text { ría de la OEl. } \\
\text { El documento está com- } \\
\text { puesto por cuatro partes } \\
\text { principales y un anexo: } \\
\text { 1. Raíces y ramas de la } \\
\text { discusión ética. } \\
\text { 2. Nuestro contexto } \\
\text { sociocultural. } \\
\text { 3. La formación de la } \\
\text { persona moral. } \\
\text { 4. Educación, ética y } \\
\text { moral. } \\
\text { 5. Marco legal y consti- } \\
\text { tucional. }\end{array}$ \\
\hline $\begin{array}{l}\text { "Contenidos } \\
\text { Transversales en los } \\
\text { nuevos planes y pro- } \\
\text { gramas». }\end{array}$ & $\begin{array}{l}\text { Ministerio de } \\
\text { Educación. }\end{array}$ & Chile. & $\begin{array}{l}\text { Refiere brevemente los } \\
\text { lineamientos de los } \\
\text { contenidos transversa- } \\
\text { les de los planes y pro- } \\
\text { gramas entre ellos: } \\
\text {-Prevención del consu- } \\
\text { mo de drogas. } \\
\text {-Fortalecimiento de los } \\
\text { valores de la conviven- } \\
\text { cia escolar. } \\
\text {-Educación ambiental. }\end{array}$ \\
\hline
\end{tabular}




\begin{tabular}{|l|l|l|l|}
\hline TíTULO & REFERENCIA & PAíS & COMENTARIOS \\
\hline $\begin{array}{l}\text { «Formación ética y } \\
\text { ciudadana». }\end{array}$ & $\begin{array}{l}\text { Ministerio de } \\
\text { Educación, Ciencia y } \\
\text { Tecnología. }\end{array}$ & Argentina. & $\begin{array}{l}\text { En este documento se } \\
\text { presentan los conteni- } \\
\text { dos básicos comunes } \\
\text { de la enseñanza del } \\
\text { Capítulo de Formación } \\
\text { Ética y Ciudadana, en } \\
\text { el Tercer Ciclo de la } \\
\text { EGB y en la Educación } \\
\text { Polimodal. }\end{array}$ \\
\hline $\begin{array}{l}\text { Innovación en educa- } \\
\text { ción en valores a nivel } \\
\text { primaria. }\end{array}$ & $\begin{array}{l}\text { Base de Datos } \\
\text { REDINET, } \\
\text { Universidad de } \\
\text { Barcelona. }\end{array}$ & España. & $\begin{array}{l}\text { Se adjunta un listado } \\
\text { de innovación en } \\
\text { materia de educación } \\
\text { en valores a nivel pri- } \\
\text { maria. }\end{array}$ \\
\hline $\begin{array}{l}\text { "Calidad y Evaluación } \\
\text { de la Educación. } \\
\text { Hacia unos centros } \\
\text { educativos de calidad. } \\
\text { Contexto, fundamento } \\
\text { y políticas de calidad } \\
\text { en la gestión escolar». }\end{array}$ & $\begin{array}{l}\text { López Rupérez } \\
\text { Francisco, } \\
\text { Eecretario General de } \\
\text { Formación y Profesional } \\
\text { del Ministerio de } \\
\text { Educación y Cultura. } \\
\text { En Ministerio de } \\
\text { Educación y Cultura. }\end{array}$ & España. & $\begin{array}{l}\text { En el apartado 3.2 del } \\
\text { documento se explica } \\
\text { la relación y caracte- } \\
\text { rística de la dimen- } \\
\text { sión ética con la cali- } \\
\text { dad de las escuelas. }\end{array}$ \\
\hline $\begin{array}{l}\text { «Values in the } \\
\text { National Currículum». }\end{array}$ & $\begin{array}{l}\text { Comunicación por } \\
\text { correo electrónico de } \\
\text { Virginia Gaywood, del } \\
\text { Business Project } \\
\text { Support Team, } \\
\text { Currículum Division. }\end{array}$ & Reino Unido. & $\begin{array}{l}\text { Este documento da } \\
\text { una visión general de } \\
\text { la forma en que se } \\
\text { trata el tema de la } \\
\text { educación en valores } \\
\text { en el currículum } \\
\text { nacional. }\end{array}$ \\
\hline "Statement of Values. & $\begin{array}{l}\text { Department for } \\
\text { Education and Skills. }\end{array}$ & Reino Unido. & $\begin{array}{l}\text { Se incluye una expli- } \\
\text { cación sobre las } \\
\text { características de los } \\
\text { valores en el currículum } \\
\text { nacional. }\end{array}$ \\
\hline
\end{tabular}




\begin{tabular}{|c|c|c|c|}
\hline TíTULO & REFERENCIA & PAíS & COMENTARIOS \\
\hline $\begin{array}{l}\text { Introducción a los } \\
\text { contenidos relaciona- } \\
\text { dos con la salud perso- } \\
\text { nal y social (PSHE) en } \\
\text { el Currículum nacional. } \\
\text { Lista de temas en el } \\
\text { Currículum nacional, } \\
\text { relacionados con la } \\
\text { salud personal y social. } \\
\text { Documento con refe- } \\
\text { rencias seleccionadas } \\
\text { de la base de datos } \\
\text { de Educación en } \\
\text { Valores de la OEl. }\end{array}$ & $\begin{array}{l}\text { Ver en apartado No. } 3 \\
\text { de este reporte. }\end{array}$ & Reino Unido. & $\begin{array}{l}\text { En la base de datos que } \\
\text { se cita, se encuentra } \\
\text { información sobre diver- } \\
\text { sos contenidos que se } \\
\text { encuentran en el currícu- } \\
\text { lum nacional, los cuales } \\
\text { están relacionados con } \\
\text { la educación en valores. }\end{array}$ \\
\hline
\end{tabular}

\section{Evaluación o Discusión sobre Prácticas a Nivel Nacional}

\begin{tabular}{|l|l|l|l|}
\hline $\begin{array}{l}\text { "Good schools, good } \\
\text { citizens: a discus- } \\
\text { sion». }\end{array}$ & $\begin{array}{l}\text { Caplan, Gerald. (1998) } \\
\text { Council of Ministers } \\
\text { of Education. }\end{array}$ & Canadá. & $\begin{array}{l}\text { A partir de cuestiona- } \\
\text { mientos sobre el papel } \\
\text { de la escuela en la for- } \\
\text { mación de ciudadanos y } \\
\text { el tipo de valores que } \\
\text { han de enseñarse en las } \\
\text { instituciones educativas, } \\
\text { este artículo presenta los } \\
\text { principales puntos de dis- } \\
\text { cusión sobre el tema de } \\
\text { la educación en valores } \\
\text { en Canadá. }\end{array}$ \\
\hline $\begin{array}{l}\text { "The leadership com- } \\
\text { pass. } \\
\text { Values and Ethics in } \\
\text { Higher education" }\end{array}$ & $\begin{array}{l}\text { Resumen realizado } \\
\text { por el Educational } \\
\text { Resources Information } \\
\text { Center (ERIC). }\end{array}$ & $\begin{array}{l}\text { Estados } \\
\text { Unidos. }\end{array}$ & $\begin{array}{l}\text { El tema que se trata en } \\
\text { este artículo puede ayu- } \\
\text { dar en la reflexión de la } \\
\text { formación inicial de } \\
\text { docentes. } \\
\text { Es posible consultar en la } \\
\text { base de datos ERIC, otros } \\
\text { resúmenes relacionados } \\
\text { con el tema. }\end{array}$ \\
\hline & & & \\
\hline
\end{tabular}




\begin{tabular}{|c|c|c|c|}
\hline TíTULO & REFERENCIA & PAÍS & COMENTARIOS \\
\hline $\begin{array}{l}\text { Organización de colo- } \\
\text { quios nacionales y } \\
\text { regionales sobre edu- } \\
\text { cación con valores. }\end{array}$ & $\begin{array}{l}\text { Secretaría de } \\
\text { Educación Pública } \\
\text { Federal y Secretarías } \\
\text { de Educación de los } \\
\text { diversos Estados de la } \\
\text { República Mexicana. }\end{array}$ & México. & $\begin{array}{l}\text { Los Coloquios Nacionales se } \\
\text { realizan anualmente en } \\
\text { algún Estado de la } \\
\text { República, trabajando coor- } \\
\text { dinadamente la Secretaría } \\
\text { de Educación Pública } \\
\text { Federal y las Secretarías de } \\
\text { Educación de los Estados. } \\
\text { Los Encuentros o Jornadas } \\
\text { Regionales son iniciativas } \\
\text { de la Secretaría de } \\
\text { Educación de los Estados de } \\
\text { la República. Los organiza- } \\
\text { dos por el Estado de Jalisco } \\
\text { son los de mayor tradición, } \\
\text { seguidos por Guanajuato, } \\
\text { Nuevo León y Baja } \\
\text { California Norte. }\end{array}$ \\
\hline $\begin{array}{l}\text { La Educación para la } \\
\text { Democracia en la } \\
\text { Transformación } \\
\text { Educativa Argentina. }\end{array}$ & $\begin{array}{l}\text { Belderrain Juan } \\
\text { Esteban. Revista } \\
\text { Latinoamericana de } \\
\text { Innovaciones } \\
\text { Educativas, n. 25, } \\
1997 .\end{array}$ & Argentina. & $\begin{array}{l}\text { Resume el estado del deba- } \\
\text { te sobre los contenidos } \\
\text { generales de la educación } \\
\text { cívica en Argentina, y carac- } \\
\text { teriza el contexto de la dis- } \\
\text { cusión. } \\
\text { Describe las características } \\
\text { distintivas de la nueva pro- } \\
\text { puesta de contenidos bási- } \\
\text { cos denominada «Formación } \\
\text { Ética y Ciudadana», en con- } \\
\text { traposición con la tradicional } \\
\text { «Educación Cívica»; enuncia } \\
\text { las propuestas fundamenta- } \\
\text { les de los Contenidos Básicos } \\
\text { Comunes y las expectativas } \\
\text { de logro aprobadas por el } \\
\text { Consejo Federal de Cultura } \\
\text { y Educación tanto para la } \\
\text { Enseñanza General Básica } \\
\text { como para el Nivel } \\
\text { Polimodal. }\end{array}$ \\
\hline
\end{tabular}




\begin{tabular}{|l|l|l|l|}
\hline TÍTULO & REFERENCIA & PAíS & COMENTARIOS \\
\hline «Values in Practice». & $\begin{array}{l}\text { Margrethe Vestager } \\
\text { (2000), Undervisnings } \\
\text { Ministeriet. }\end{array}$ & Dinamarca. & $\begin{array}{l}\text { Es una reflexión que rea- } \\
\text { liza la actual ministra de } \\
\text { educación de Dinamarca } \\
\text { sobre sus ideas acerca } \\
\text { de los valores y cómo } \\
\text { éstos deben estar pre- } \\
\text { sentes en el sistema } \\
\text { educativo. }\end{array}$ \\
\hline
\end{tabular}

\section{Propuestas Teórico Metodológicas}

\begin{tabular}{|c|c|c|c|}
\hline $\begin{array}{l}\text { «La Educación en } \\
\text { Valores: una propues- } \\
\text { ta pedagógica para la } \\
\text { formación profesio- } \\
\text { nal». }\end{array}$ & $\begin{array}{l}\text { Arana Ercilla Martha } \\
\text { y Batista Tejeda } \\
\text { Martha. ISPAJAE } \\
\text { Cuba. En Organización } \\
\text { de Estados } \\
\text { lberoamericanos para } \\
\text { la Educación, la } \\
\text { Ciencia y la Cultura. }\end{array}$ & Cuba. & $\begin{array}{l}\text { Este artículo se inicia con } \\
\text { un tratamiento conceptual } \\
\text { del tema para llegar a un } \\
\text { modelo de formación de } \\
\text { valores del profesional de } \\
\text { Ingeniería y Arquitectura, } \\
\text { y una metodología para la } \\
\text { determinación de los valo- } \\
\text { res a desarrollar en la } \\
\text { carrera, año, disciplina y } \\
\text { asignatura. }\end{array}$ \\
\hline $\begin{array}{l}\text { «Sociedad, valores y } \\
\text { educación». }\end{array}$ & $\begin{array}{l}\text { Pérez Juste Ramón. } \\
\text { Ponencia presentada } \\
\text { en el Seminario sobre } \\
\text { Sociedad, Valores y } \\
\text { Educación, marzo de } \\
1997 .\end{array}$ & España. & $\begin{array}{l}\text { Plantea, desde la pers- } \\
\text { pectiva pedagógica, tres } \\
\text { grandes cuestiones: } \\
\text { - Qué características de } \\
\text { la sociedad actual repre- } \\
\text { sentan una exigencia a } \\
\text { los sistemas educativos } \\
\text { para que asuman la edu- } \\
\text { cación en valores. } \\
\text { - Qué relación se da } \\
\text { entre la educación en } \\
\text { valores y la educación de } \\
\text { calidad. } \\
\text { - Oué líneas de acción } \\
\text { pueden configurar un sis- } \\
\text { tema de educación en } \\
\text { valores. }\end{array}$ \\
\hline
\end{tabular}




\begin{tabular}{|c|c|c|c|}
\hline TíTULO & REFERENCIA & PAÍS & COMENTARIOS \\
\hline $\begin{array}{l}\text { «La evaluación en } \\
\text { Educación en } \\
\text { Valores». }\end{array}$ & $\begin{array}{l}\text { Aldea López Eliana. } \\
\text { Consejera educacio- } \\
\text { nal y vocacional, coor- } \\
\text { dinadora de progra- } \\
\text { mas: Educación en } \\
\text { Valores I. } \\
\text { Municipalidad de } \\
\text { Chillán-Chile. } \\
\text { En Organización de } \\
\text { Estados } \\
\text { lberoamericanos para } \\
\text { la Educación, la } \\
\text { Ciencia y la Cultura. }\end{array}$ & Chile. & $\begin{array}{l}\text { Es una reflexión-propues- } \\
\text { ta sobre la evaluación en } \\
\text { valores. }\end{array}$ \\
\hline $\begin{array}{l}\text { "El vigor de los valo- } \\
\text { res morales para la } \\
\text { convivencia». }\end{array}$ & $\begin{array}{l}\text { Cortina Orts Adela. } \\
\text { Ponencia presentada } \\
\text { en el Seminario sobre } \\
\text { Sociedad, Valores y } \\
\text { Educación, marzo de } \\
1997 .\end{array}$ & España. & $\begin{array}{l}\text { Presenta los que, a su jui- } \\
\text { cio, son los valores mora- } \\
\text { les de los que no se } \\
\text { puede retroceder y en los } \\
\text { que se debe educar en la } \\
\text { escuela, en la familia y en } \\
\text { una sociedad que se } \\
\text { denomine pluralista. }\end{array}$ \\
\hline
\end{tabular}




\section{REFERENCIAS BIBLIOGRÁFICAS}

ARENDT, Hannah., Sobre la violencia., Cuadernos de Joaquín Moritz., México., 1970.

BRAUDEL, Ferdinand., La dinámica del capitalismo., México., FCE., 1986.

COOMBS, Philiph H., La crisis mundial de la educación., Ediciones Península., Barcelona., 1978.

DELORS, Jacques., La educación encierra un tesoro., México., Ediciones UNESCO., 1997.

GRUNDWALT, Joseph y KENNETH Flamm., La fábrica mundial. El ensamblaje extranjero en el comercio internacional., México., FCE., 1991.

IANNI, Octavio., Teorias de la globalización., México., Siglo XXI., 1997.

MCLUHAN, Marshall y POWERS, Bruce R.., La aldea global. Transformaciones en la vida y los medios de comunicación mundiales en el siglo XX., Gedisa., 1991.

PHILIPSON, Robert., Linguistic Imperialism., Oxford., Oxford University Press., 1992.

SINGH, Karan., "Educar en la sociedad global", en DELORS, Jacques., La educación encierra un tesoro., México., Ediciones UNESCO., 1997.

TRUCHOT, Claude., L'Anglais dans le monde contemporain., Paris., Le Robert., 1990.

WALLWERSTEIN, Immanuel., "Análisis del sistema-mundo", en GIDDENS, Anthony y TURNER, Jonathan H. (edit)., Teoría Social, hoy., Madrid., Alianza., 1990.

Diccionario de la Real Academia Española., Madrid., 1970. Reporte de Documentación Internacional sobre Educación en Valores (compilado por NAIME Nadina y OCAMPO GRANADOS, Ma. Eugenia., Dirección General de Relaciones Internacionales., SEP., 2002. 